\title{
BMJ Open Economic evaluation of different routes of surgery for the management of endometrial cancer: a retrospective cohort study
}

\author{
Esther L Moss (D) , , ${ }^{1,2}$ George Morgan, ${ }^{3}$ Antony Martin, ${ }^{3}$ Panos Sarhanis, ${ }^{4}$ \\ Thomas Ind ${ }^{5,6}$
}

\begin{abstract}
To cite: Moss EL, Morgan G, Martin A, et al. Economic evaluation of different routes of surgery for the management of endometrial cancer: a retrospective cohort study. BMJ Open 2021;11:e045888. doi:10.1136/ bmjopen-2020-045888
\end{abstract}

- Prepublication history and supplemental material for this paper is available online. To view these files, please visit the journal online (http://dx.doi org/10.1136/bmjopen-2020045888).

Received 18 0ctober 2020 Revised 22 April 2021 Accepted 27 April 2021

Check for updates

(C) Author(s) (or their employer(s)) 2021. Re-use permitted under CC BY-NC. No commercial re-use. See rights and permissions. Published by BMJ.

${ }^{1}$ Leicester Cancer Research Centre, University of Leicester, Leicester, UK

${ }^{2}$ Department of Gynaecological Oncology, University Hospitals of Leicester, Leicester, UK

${ }^{3} \mathrm{HCD}$ Economics, Daresbury, Cheshire, UK

${ }^{4}$ Department of Gynaecology, North West London Hospitals NHS Trust, London, UK ${ }^{5}$ Department of Gynaecological Oncology, Royal Marsden Hospital, London, UK

${ }^{6}$ Department of Gynaecology, St George's University of London, London, UK

Correspondence to

Dr Esther L Moss;

em321@le.ac.uk

\section{ABSTRACT}

Objectives The benefits of minimally invasive

surgery (MIS) for endometrial carcinoma (EC) are well established although the financial impact of roboticassisted hysterectomy $(\mathrm{RH})$ compared with laparoscopic hysterectomy $(\mathrm{LH})$ is disputed.

Design Retrospective cohort study.

Setting English National Health Service hospitals 20112017/2018.

Participants 35304 women having a hysterectomy for EC identified from Hospital Episode Statistics.

Primary and secondary outcome measures The primary outcome was the association between route of surgery on cost at intervention, 30, 90 and 365 days for women undergoing an open hysterectomy $(\mathrm{OH})$ or MIS ( $\mathrm{LH} /$ $\mathrm{RH})$ for EC in England. The average marginal effect was calculated to compare $\mathrm{RH}$ versus $\mathrm{OH}$ and $\mathrm{RH}$ versus $\mathrm{LH}$ which adjusted for any differences in the characteristics of the surgical approaches. Secondary outcomes were to analyse costing data for each surgical approach by age, Charlson Comorbidity Index (CCl) and hospital MIS rate classification.

Results A total of 35304 procedures were performed, 20405 (57.8\%) were MIS (LH: 18604 and RH: 1801), $14291(40.5 \%)$ OH. Mean cost for LH was significantly less than $\mathrm{RH}$, whereas $\mathrm{RH}$ was significantly less than $\mathrm{OH}$ at intervention, 30,90 and 365 days $(p<0.001)$. Over time, patients who underwent $\mathrm{RH}$ had increasing $\mathrm{CCl}$ scores and by the $2015 / 2016$ year had a higher average CCI than $\mathrm{LH}$. Comparing the cost of $\mathrm{LH}$ and $\mathrm{RH}$ against CCl score identified that the costs closely reflected the patients' $\mathrm{CCl}$. Increasing disparity was also seen between the MIS and $\mathrm{OH}$ costs with rising age. When exploring the association between provider volume, MIS rate and surgical costs, there was an association with the higher the MIS rate the lower the average cost.

Conclusions Further research is needed to investigate costs in matched patient cohorts to determine the optimum surgical modality in different populations.

\section{INTRODUCTION}

The introduction of minimally invasive surgery (MIS) for endometrial cancer (EC) has had a dramatic impact on patients surgical outcomes with reduced morbidity,
Strengths and limitations of this study

- The findings from the study are based on a population-based database which is a key strength as it is representative of all procedures via the National Health Service in England.

- The reliability of the coding might have changed over time although there was no evidence of changes in treatment coding or significant changes in the underlying study population.

- The Hospital Episode Statistics (HES) Database reliably captures extensive amount of demographic, diagnosis and procedure outcomes; however, there is a lack of cancer stage information therefore it is not possible to split out the cost outcomes into more specific groups of patients.

- The capital and maintenance costs of roboticassisted hysterectomy have not been included since these costs vary dramatically across different healthcare settings and are often used by a wide group of specialties in a hospital setting.

- As the analysis was undertaken over a number of years of the HES Database, we were able to accurately follow hospital activity for at least a year after intervention.

hospital stay and improved short-term quality of life. ${ }^{1}$ Translating these patient benefits into cost benefits to the healthcare economy has been challenging because although MIS requires significantly less bed-days than open surgery, it does require more costly consumable equipment, for example, single-use vessel-sealing devices. This has been demonstrated in several studies including the multicentre randomised LACE trial where the surgery costs were greater for laparoscopic hysterectomy (LH) compared with open hysterectomy $(\mathrm{OH})$, but the overall costs of treatment were lower. ${ }^{2}$

MIS is the preferred surgical route for EC. ${ }^{3}$ Robotic-assisted hysterectomy (RH) is accepted as an alternative to LH, supported 
by evidence from a randomised controlled trial (RCT) ${ }^{4}$ and $\mathrm{RH}$ has been shown to have a lower conversion rate to laparotomy and shorter operating time..$^{5-7}$ Widespread adoption of RH is limited in England, although the number of EC cases having RH is increasing year on year. ${ }^{8}$ In light of the capital and consumable costs of RH, as compared with $\mathrm{OH}$ or $\mathrm{LH}$, the use of $\mathrm{RH}$ in $\mathrm{EC}$ is therefore being called into question. ${ }^{6}$ Reports from institutions with well-established robotic programmes however have contested this view with no significant difference, ${ }^{9}$ or cost improvements reported as compared with $\mathrm{LH} .{ }^{10}$ What is clear is that focusing solely on in-hospital costs does not give the full picture of the economic costs of a surgical procedure, since many costs are accrued following discharge or attributed to the economy as a whole as a result of delayed return to employment.

We therefore investigated the Hospital Episode Statistics (HES) data for England in order to look at the financial impact of $\mathrm{RH}$ as compared with $\mathrm{LH}$ and $\mathrm{OH}$. We also investigated the patient characteristics that contributed to cost and examined the top 5\% of procedures to identify factors that may have contributed to the costs.

\section{METHODS}

\section{Data source and cohort selection}

Data were sourced from the HES Database from 20112017/2018. ${ }^{11}$ The HES Database captures demographic, diagnosis and procedure outcomes data however does not include cancer stage or histology information. Patients or the public were not involved in the design, or conduct or reporting of our research. The inclusion criterion for patients was a diagnosis of EC or EC in situ/ complex atypical hyperplasia (ECIS) undergoing a hysterectomy between October 2011 and December 2017. The surgical approach was classified by intention-to-treat as $\mathrm{OH}$, vaginal hysterectomy (VH), LH, RH and MIS which was the combination of $\mathrm{LH}$ and RH. Due to the low numbers, the $\mathrm{VH}$ cases were not included in any of the subsequent analyses. The cohort selection for the study has been described in more detail previously ${ }^{8}$ and the list of specific diagnosis (ICD-10) and procedure (OPCS-4.7) codes can be found in the online supplemental table A1.

\section{Patient characteristics}

Demographic data were captured in the hospital admission data for each patient and included age, ethnicity, postcode and comorbidities. Patient age was divided by 10-year intervals from the age of 50 years into six groups. Ethnicity was classified into Asian, Black, other and White ethnicity. Based on postcode of residence, each patient who received EC surgery was mapped to the English Index of Multiple Deprivation (IMD) rank. The IMD indicates the socioeconomic deprivation of patients which combines seven indicators (income; employment; health deprivation and disability; education, skills and training; barriers to housing and services; crime; and living environment), into a single deprivation index where a higher rank indicated a less deprived group and a lower rank indicated a more deprived group. ${ }^{12}$ The IMD was split into statistical quartiles and indicated whether the sociodemographic status was high $(>25083)$, intermediate (17475-25 083), low (9618-17 474) or very low $(<9618)$ for each patient. Comorbidities were examined 12 months prior to intervention using the Charlson Comorbidity Index (CCI) ${ }^{13}$ An additional list of other comorbidities was also assessed using specific ICD-10 codes (online supplemental table A2).

Hospital characteristics were assessed by region (East, East Midlands, Greater London, Home Counties, North East, North West, South East, South West, West Midlands, Yorkshire) and volume, which was based on the annual mean of hysterectomies performed for EC/ ECIS grouped by statistical quartiles (high $(>220)$, intermediate (71-220), low (21-70) and very low (0-20)). MIS rates of hospitals for EC/ECIS hysterectomy procedures were classified into four groups based on percentage of hysterectomies performed by MIS approach (high $(76 \%-$ $100 \%)$, intermediate $(51 \%-75 \%)$, low $(26 \%-50 \%)$ and very low $(0 \%-25 \%))$.

\section{Outcomes}

For each patient episode, in the HES database, a cost is assigned based on the Health Resource Group (HRG) which is diagnosis/procedure-based grouping and the length of stay. These costs are based on reference costs provided by each hospital and are estimated based on recorded inpatient, outpatient, and Accident and Emergency episode activity in the HES Database using National Health Service (NHS) Payment by Results HRG tariffs. ${ }^{14}$ Costs at intervention and short-term costs were calculated based on the reported hospital admission costs over the time period of 30,90 and 365 days following intervention, these were all summarised by procedure approach. Further to this, the cost of each approach was assessed by the subgroups of age, CCI groups and MIS rate classification. A list of non-surgical cancer-related treatments was collated (see online supplemental table A3 for specific OPCS-4.7 procedure codes) and these costs were excluded in the analysis. Perioperative outcomes included mortality, conversion to $\mathrm{OH}$ and length of stay. The 90-day outcomes included the mortality, total and specific inpatient, outpatient and emergency readmissions. Subgroup analyses were performed, first to assess high-cost (HC) (top 5\% of costs at intervention by approach) and low-cost (LC) patients (lowest $50 \%$ of costs at intervention by approach) in the cohort to assess what was driving HC patients. In addition, provider-level analysis was conducted to assess hospital characteristics and costs to further understand the impact of differing MIS rates and volume sizes.

\section{Statistical analyses}

A descriptive analysis of patient characteristics and data on costs and other health resource was performed. The different approaches (LH, RH, OH, MIS) were then 
compared by using t-test (for independent samples) and Wilcoxon rank-sum test (Mann-Whitney U test) for continuous variable and for categorical variables by using the $\mathrm{X}^{2}$ tests. The average marginal effect $(\mathrm{AME})^{15}$ was used to compare RH versus $\mathrm{OH}$ and $\mathrm{RH}$ versus $\mathrm{LH}$ on costing outcomes at intervention, 30 days, 90 days and 365 days. This approach adjusted for patient age, ethnicity, IMD rank, CCI, year of procedure and whether a patient received cancer treatment following the intervention (for further details, see online supplemental table A3) by fitting Generalised Linear Models. The Modified Park Test and Pregibon's Link Test ${ }^{16}$ were used to ensure the most efficient model structure was used to model the costs. All statistical analyses were performed using Stata V.15.

\section{Patient and public involvement}

There was no patient or public involvement in the study planning or design.

\section{RESULTS}

A total of 35304 procedures were performed: 18604 (52.7\%) LH, 1801 (5.1\%) RH, 14291 (40.5\%) OH and $608(1.7 \%) \mathrm{VH}$. The proportion of MIS cases increased significantly over time each year from $46.6 \%$ in $2012 / 2013$ to $68.7 \%$ in $2016 / 2017$ ( $p<0.001$ ). This was primarily due to an increase in LH of $15.8 \%(44.7 \%$ to $60.5 \%)$, but there was also a $6.2 \%$ increase $(2.0 \%$ to $8.2 \%$ ) in the number of $\mathrm{RH}$ performed when comparing 2012/2013 with 2016/2017 as a proportion of all surgeries performed each year. Consequently, the number of $\mathrm{OH}$ cases decreased significantly over time $(\mathrm{p}<0.001)$ from $53.4 \%$ in $2012 / 2013$ to $31.3 \%$ in $2016 / 2017$ of cases in that year.

Table 1 presents the patient characteristics of the surgical approaches LH, RH and $\mathrm{OH}$. Most cases were performed at high-volume providers ( $>220$ cases/year) with $72.4 \%$ for RH, $62.1 \%$ for $\mathrm{LH}$ and $60.9 \%$ for $\mathrm{OH}$ being undertaken at these providers (table 1). As previously described, there was a significant difference in the social/ ethnic characteristics of the patients undergoing MIS as compared with $\mathrm{OH}$ within this cohort of patients. ${ }^{8}$ The characteristics of the RH population differed to patients undergoing LH; with a significantly higher percentage of RH patients having any comorbidity from our defined list than LH $(68.2 \%$ vs $64.0 \%, \mathrm{p}<0.001)$, more specifically the comorbidities of diabetes, hypertension and obesity all being higher proportion in RH cohort than LH cohort.

\section{Short-term costs by approach}

The short-term costs of intervention, 30 days, 90 days and 365 days by surgical approach are presented in table 2 . LH was associated with the lowest mean cost at the intervention (£3069), 30 (£3083), 90 (£3111) and 365 (£3169) days following the procedure. The mean cost for $\mathrm{RH}$ was significantly less than $\mathrm{OH}$ at all the time points $(\mathrm{p}<0.001$ for all). The AME for RH versus $\mathrm{OH}$, controlling for patient characteristics, also showed a significant difference for $\mathrm{RH}$ over $\mathrm{OH}$ with the difference in cost increasing when comparing the unadjusted and AME value $(\mathrm{p}<0.001$ for all). Comparing RH and LH short-term costs, LH costs were significantly lower for the unadjusted and AME differences ( $<<0.001$ for all). The AME differences in cost between RH and LH were lower compared with the unadjusted differences (eg, AME difference of $£ 108$ vs unadjusted difference of $£ 260$ at intervention).

\section{HC and LC patient comparison}

Assessing the top 5\% HC patients of each approach (LH: $\mathrm{n}=336$; OH: $\mathrm{n}=593, \mathrm{RH}: \mathrm{n}=27$ ) and comparing with the LC cohort, which was set at less than or equal to the median cost of the surgery (LH: $n=12913$; OH: $n=9021$, RH: $\mathrm{n}=812$ ). The patients in the HC group were significantly older in all the routes of surgery (LH: 69.0 vs 65.7 years, OH: 68.8 vs 65.1 years, RH: 67.5 vs 65.5 years: $p<0.001$ for all). The HC cohort contained a higher percentage of patients from the lower socioeconomic groups (IMD rank: 16637 vs $17287, \mathrm{p}<0.001$ ) and patients from ethnic minority groups $(29.6 \%$ vs $19.2 \%, \mathrm{p}<0.001)$ as compared with the LC cohort. Patients in the HC cohort also had significantly greater number of comorbidities compared with the LC cohort (CCI 1.82 vs 1.41 and any comorbidity $71.0 \%$ vs $63.9 \%$; $<<0.001$ for all). The length of hospital stay was significantly longer in the $\mathrm{HC}$ cases compared with the LC group (RH: 11.22 vs 1.84 days; LH: 11.42 vs 2.03 days; $\mathrm{OH}$ : 20.82 vs 3.71 days; $\mathrm{p}<0.001$ for all). Although the rate of complications was greater in the $\mathrm{HC}$ compared with the LC cohort (RH: $55.6 \%$ vs $14.0 \%$; LH: $61.0 \%$ vs $16.2 \%$; OH: $71.5 \%$ vs $19.1 \%$; $\mathrm{p}<0.001$ for all), the rate was significantly lower with $\mathrm{RH}$ as compared with $\mathrm{OH}$ in both the HC and LC groups (HC: $55.6 \%$ vs $71.5 \%$, $\mathrm{p}=0.075$; LC: $14.0 \%$ vs $19.1 \%, \mathrm{p}<0.001)$.

\section{Patient characteristics and costs}

Patient characteristics, age and CCI were associated with increasing costs for almost all routes of surgery at intervention, and 365 days following the procedure (table 3). Assessing the age categories showed the costs at intervention were very similar for the groups $<50$ years, $50-59$ years and 60-69 years but gradually increased for each of the higher age groups. There was an increasing difference between the MIS and $\mathrm{OH}$ costs with rising age with the difference between MIS and $\mathrm{OH}$ for age $<50$ years being $£ 258$ increasing to a difference of $£ 653$ for the population aged $>90$ years. RH 365-day costs were significantly lower $(\mathrm{p}<0.01)$ than $\mathrm{OH}$ in all age categories except $60-69$ and $>90$ years. Comparing CCI showed that CCI group $\geq 3$ was associated with the greatest difference in costs with the difference at 365 days between CCI group 1 and CCI group $\geq 3$ being $£ 130$ for $\mathrm{RH}, £ 174$ for LH and $£ 759$ for $\mathrm{OH}$ (table 3).

Over time, patients who underwent RH had increasing levels of comorbidities, when using the CCI score, and have in recent years had a higher average CCI than LH in 2015/2016-2016/2017 (figure 1). Comparing the cost 
Table 1 Clinical and demographic characteristics by the cohorts of hysterectomy approach

\section{Unadjusted results}

\begin{tabular}{|c|c|c|c|c|c|c|c|c|}
\hline \multirow[b]{4}{*}{ Characteristics } & \\
\hline & \multirow{2}{*}{\multicolumn{2}{|c|}{$\begin{array}{l}\text { Laparoscopic } \\
\text { Hysterectomy } \\
(\mathrm{N}=18604) \\
\end{array}$}} & \multirow{2}{*}{\multicolumn{2}{|c|}{$\begin{array}{l}\text { Robotic } \\
\text { Hysterectomy } \\
\text { (N=1801) }\end{array}$}} & \multirow{2}{*}{\multicolumn{2}{|c|}{$\begin{array}{l}\text { MIS } \\
\text { Hysterectomy } \\
(\mathrm{N}=20405)\end{array}$}} & \multirow{2}{*}{\multicolumn{2}{|c|}{$\begin{array}{l}\text { Open } \\
\text { Hysterectomy } \\
(\mathrm{N}=14291)\end{array}$}} \\
\hline & & & & & & & & \\
\hline & No & (\%) & No & (\%) & No & $(\%)$ & No & $(\%)$ \\
\hline \multicolumn{9}{|l|}{ NHS year of surgery } \\
\hline $2011 / 2012^{*}$ & 1108 & 6 & 19 & 1 & 1127 & 6 & 1671 & 12 \\
\hline $2012 / 2013$ & 2367 & 13 & 104 & 6 & 2471 & 12 & 2829 & 20 \\
\hline $2013 / 2014$ & 2824 & 15 & 147 & 8 & 2971 & 15 & 2614 & 18 \\
\hline $2014 / 2015$ & 3134 & 17 & 253 & 14 & 3387 & 17 & 2361 & 17 \\
\hline $2015 / 2016$ & 3118 & 17 & 382 & 21 & 3500 & 17 & 1948 & 14 \\
\hline $2016 / 2017$ & 3577 & 19 & 483 & 27 & 4060 & 20 & 1852 & 13 \\
\hline $2017 / 2018^{*}$ & 2476 & 13 & 413 & 23 & 2889 & 14 & 1016 & 7 \\
\hline \multicolumn{9}{|l|}{ Age, years } \\
\hline$<50$ & 1033 & 6 & 120 & 7 & 1153 & 6 & 1082 & 8 \\
\hline $50-59$ & 3937 & 21 & 380 & 21 & 4317 & 21 & 3098 & 22 \\
\hline $60-69$ & 6522 & 35 & 589 & 33 & 7111 & 35 & 4672 & 33 \\
\hline $70-79$ & 5160 & 28 & 533 & 30 & 5693 & 28 & 3779 & 26 \\
\hline $80-89$ & 1846 & 10 & 174 & 10 & 2020 & 10 & 1540 & 11 \\
\hline$>90$ & 106 & 1 & 5 & 0 & 111 & 1 & 120 & 1 \\
\hline \multicolumn{9}{|l|}{ Ethnicity } \\
\hline White & 15033 & 81 & 1420 & 79 & 16453 & 81 & 11117 & 78 \\
\hline Asian & 583 & 3 & 66 & 4 & 649 & 3 & 499 & 3 \\
\hline Black & 231 & 1 & 20 & 1 & 251 & 1 & 365 & 3 \\
\hline Other & 2757 & 15 & 295 & 16 & 3052 & 15 & 2310 & 16 \\
\hline \multicolumn{9}{|c|}{ Socioeconomic group (IMD) } \\
\hline High & 4506 & 25 & 643 & 37 & 5149 & 25 & 3291 & 23 \\
\hline Intermediate & 4612 & 25 & 403 & 23 & 5015 & 25 & 3387 & 24 \\
\hline Low & 4548 & 25 & 376 & 21 & 4924 & 24 & 3489 & 24 \\
\hline Very low & 4435 & 25 & 333 & 19 & 4768 & 23 & 3703 & 26 \\
\hline \multicolumn{9}{|c|}{ Charlson Comorbidity group } \\
\hline 0 & 22 & 0 & 1 & 0 & 23 & 0 & 13 & 0 \\
\hline 1 & 12432 & 67 & 1159 & 64 & 13591 & 67 & 8405 & 59 \\
\hline 2 & 4915 & 26 & 514 & 29 & 5429 & 27 & 4535 & 32 \\
\hline$\geq 3$ & 1235 & 7 & 127 & 7 & 1362 & 7 & 1338 & 9 \\
\hline \multicolumn{9}{|l|}{ Region } \\
\hline Greater London & 2529 & 14 & 319 & 18 & 2848 & 14 & 2184 & 15 \\
\hline Yorkshire & 1501 & 8 & 270 & 15 & 1771 & 9 & 1220 & 9 \\
\hline West Midlands & 1747 & 9 & 154 & 9 & 1901 & 9 & 1672 & 12 \\
\hline South West & 2676 & 14 & 75 & 4 & 2751 & 13 & 1348 & 9 \\
\hline South East & 1746 & 9 & 339 & 19 & 2085 & 10 & 1451 & 10 \\
\hline North West & 2628 & 14 & 281 & 16 & 2909 & 14 & 2550 & 18 \\
\hline North East & 1264 & 7 & 138 & 8 & 1402 & 7 & 432 & 3 \\
\hline Home Counties & 1095 & 6 & 31 & 2 & 1126 & 6 & 912 & 6 \\
\hline East Midlands & 1485 & 8 & 165 & 9 & 1650 & 8 & 1003 & 7 \\
\hline East & 1922 & 10 & 4 & 0 & 1926 & 9 & 1497 & 10 \\
\hline
\end{tabular}




\begin{tabular}{|c|c|c|c|c|c|c|c|c|}
\hline \multirow[b]{4}{*}{ Characteristics } & \multicolumn{8}{|c|}{ Unadjusted results } \\
\hline & \multirow{2}{*}{\multicolumn{2}{|c|}{$\begin{array}{l}\text { Laparoscopic } \\
\text { Hysterectomy } \\
(\mathrm{N}=18604)\end{array}$}} & \multirow{2}{*}{\multicolumn{2}{|c|}{$\begin{array}{l}\text { Robotic } \\
\text { Hysterectomy } \\
(\mathrm{N}=1801)\end{array}$}} & \multirow{2}{*}{\multicolumn{2}{|c|}{$\begin{array}{l}\text { MIS } \\
\text { Hysterectomy } \\
(\mathrm{N}=20405)\end{array}$}} & \multirow{2}{*}{\multicolumn{2}{|c|}{$\begin{array}{l}\text { Open } \\
\text { Hysterectomy } \\
(\mathrm{N}=14291)\end{array}$}} \\
\hline & & & & & & & & \\
\hline & No & $(\%)$ & No & $(\%)$ & No & $(\%)$ & No & (\%) \\
\hline Missing & 11 & 0 & 25 & 1 & 36 & 0 & 22 & 0 \\
\hline High & 11423 & 62 & 1302 & 72 & 12725 & 62 & 8703 & 61 \\
\hline Intermediate & 6653 & 36 & 487 & 27 & 7140 & 35 & 5102 & 36 \\
\hline Low & 279 & 2 & 9 & 1 & 288 & 1 & 191 & 1 \\
\hline Very low & 36 & 0 & 0 & 0 & 36 & 0 & 58 & 0 \\
\hline Missing & 213 & 1 & 3 & 0 & 216 & 1 & 237 & 2 \\
\hline
\end{tabular}

*NHS year 2011/2012 and 2017/2018 not full year.

IMD, Index of Multiple Deprivation; MIS, minimally invasive surgery; NHS, National Health Service.

of LH and RH against CCI score identified that the costs closely reflected the patients' CCI. In 2012/2013 when the RH population had a lower CCI then the costs were less; however, since 2014/2015, the patient population undergoing RH had higher CCI score and this was associated with a rise in the costs of RH above that of LH (figure 1).

\section{Hospital characteristics and costs}

When exploring the association between provider volume, MIS rate and surgical costs, there was an association with the MIS rate and cost, that is, the greater the MIS rate the lower the cost (figure 2). Many of the highest volume providers had higher average costs than providers with less volume, however the patient population undergoing surgery at the high-volume providers were significantly older and had a higher CCI compared with the lower volume providers (age: 66.2 vs 65.6 years, $p<0.001$; CCI: 1.47 vs $1.43, \mathrm{p}<0.001)$. The majority of the highest volume providers had MIS rates between $50 \%$ and $90 \%$ and the relationship held for high-volume providers with average costs decreasing as MIS rates increased for the year 2016/2017.

\section{DISCUSSION}

\section{Main findings}

In this study, we have performed an in-depth analysis of real-world data and have identified financial benefits of MIS as compared with OH for EC. We have demonstrated that LH has the lowest mean cost at intervention and that costs increased with increasing patient age. In keeping with other studies, we have also shown that $\mathrm{OH}$, although attracting the lowest operative consumable costs, had the greatest overall financial cost, even significantly higher than RH. We have also identified that although the cost of $\mathrm{RH}$ is greater than $\mathrm{LH}$, patients undergoing $\mathrm{RH}$ have different characteristics compared with women having $\mathrm{LH}$ in recent years, and that cost of surgery appears to be influenced by level of patients' comorbidities and not the route of surgery alone.

There will always be a proportion of cases that have to be performed $\mathrm{OH}$ due to contraindications/complications with MIS, which will inevitably attract higher costs due to their complexity, but this can be reduced to low levels. ${ }^{17}$ The significantly higher complication/readmission rate with $\mathrm{OH}$ has been reported previously ${ }^{8}$ and in this study we have shown that even in the HC groups, the complication rate was higher with $\mathrm{OH}(71.5 \%)$ as compared with RH (55.6\%) and LH (61.0\%). A longer recovery time may impact on patient and employment costs, with greater loss of earnings and longer return to work or contribution to society activities as compared with MIS. Korsholm $e t a l^{18}$ reported no significant difference in return to the labour market or use of sickness benefits in a study from Denmark, however; in their study, robotic surgery was associated with greater cost than both LH and $\mathrm{OH}$, unlike this UK analysis. Allowing for a number of $\mathrm{OH}$ cases, the disparity in MIS uptake across England ${ }^{8}$ does indicate that there is room for improvement in increasing the proportion of MIS cases thereby benefiting both the patient and the healthcare economy.

The primary argument used against the widespread use of $\mathrm{RH}$, rather than $\mathrm{LH}$, for EC is an economic one, ${ }^{6} 19$ since the clinical outcomes are reported to be comparable although, there is a lack of RCT data, particular in patients with a high body mass index (BMI). ${ }^{20}$ The HES data do confirm a cost advantage for LH over RH, however, the two patient populations are not directly comparable since there is a significant difference in the CCIs between the groups. During 2012/2013, when RH was only performed in a few selected centres, the majority of UK robotic surgeons would still have been within the learning phase, and therefore likely to select patients with less comorbidities for RH. We have shown that during this time period, the cost of RH was less than LH. Increasing robotics 


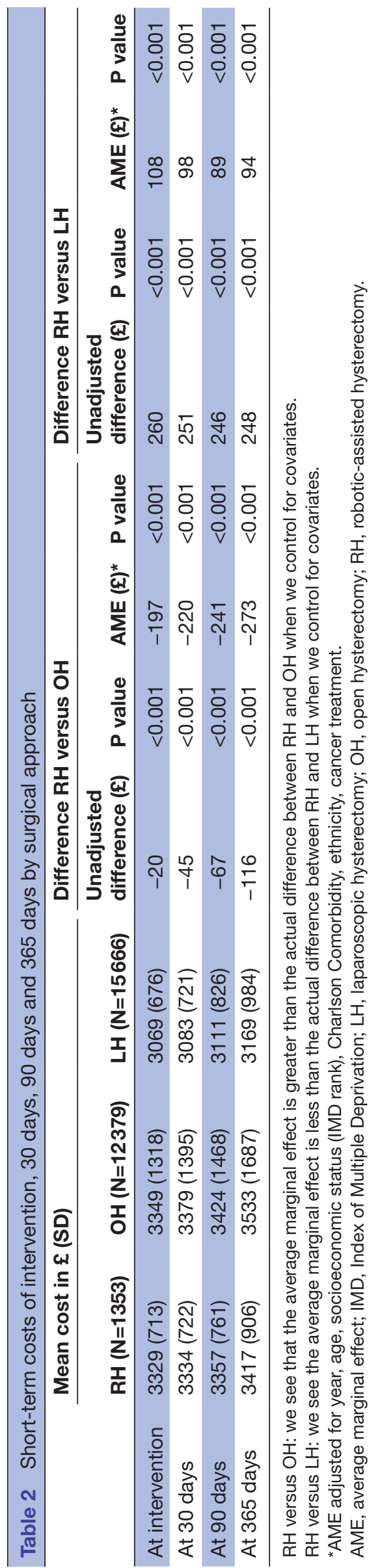

experience appears to have led to the positive selection of comorbid patients, especially high BMI, for $\mathrm{RH}$, and this is associated with rising costs. Class III obesity and a rising number of patient comorbidities are reported to attract increased inpatient care costs due to increased medical rather than surgical complications associated with undergoing surgery. ${ }^{21} 22$ The selection of patients with a high BMI for RH is not unexpected given the reported ergonomic benefits for surgeons as compared with straightstick laparoscopy, ${ }^{23}$ with less movements and muscle activity required to perform tasks. ${ }^{24} \mathrm{RH}$ is not without issues due to the fixed console position, ${ }^{25}$ however more extreme muscle movements are required to perform laparoscopic procedures with increasing BMI, ${ }^{24}$ which is not reported with robotics. The cost to the healthcare service of work-related musculoskeletal symptoms in surgeons is of growing concern ${ }^{26}$ and not considered in economic analyses such as this study, however it is an additional cost that needs to be considered when calculating service delivery costs.

What is clear from the data is that $\mathrm{OH}$ is the most costly route of surgery, a finding reported in other healthcare settings, ${ }^{27}$ not only in financial terms but more importantly for patient complications and postoperative mortality. ${ }^{8}$ The key focus therefore, rather than being between LH and RH, should instead be on reducing the $\mathrm{OH}$ rate to a minimum. Although there are only a few absolute contraindications for $\mathrm{OH}$, the number of cases that are performed through open surgery is still high in some institutions and there has been much discussion how this could be reduced through greater surgical training ${ }^{28}$ or centralisation of cases to hospitals and surgeons with high MIS rates. ${ }^{29}$ A reduction in $\mathrm{OH}$ can also be achieved through reducing the number of conversions from $\mathrm{LH} / \mathrm{RH}$ to a minimum. A meta-analysis of observational studies did show that the conversion rate of LH increased with BMI $>40 \mathrm{~kg} / \mathrm{m}^{2}$ more than for RH, $6.5 \%(95 \%$ CI $4.3 \%$ to $9.9 \%)$ vs $5.5 \%$ (95\% CI $3.3 \%$ to $9.1 \%$ ), as compared with $>30 \mathrm{~kg} / \mathrm{m}^{2}, 7.0 \%$ (95\% CI $3.2 \%$ to $14.5 \%$ ) vs $3.8 \%$ (95\% CI $1.4 \%$ to $99 \%$ ), respectively. ${ }^{20}$ One reason for this may be the lower intra-abdominal insufflation pressure often used with $\mathrm{RH}$, typically $8 \mathrm{~mm}$ $\mathrm{Hg}$, which has been shown to be associated with lower postoperative pain and shorter hospital stay as compared with a pressure $15 \mathrm{~mm} \mathrm{Hg} .{ }^{30}$ Inability to tolerate Trendelenburg position was also reported to be the indication for $31 \%$ of LH conversions but only $6 \%$ of RH conversions. ${ }^{20}$ This therefore raises the possibility as to whether cases should be selected for $\mathrm{RH}$ where there is high risk of conversion due to class III obesity or inability to tolerate the pneumoperitoneum. Further research is needed to compare the clinical outcomes and costs of LH and RH in matched populations, for example, BMI $>40 \mathrm{~kg} / \mathrm{m}^{2}$ or previous abdominal surgery, to investigate whether differences reported in retrospective case series are confirmed. Such trials would determine whether certain patient characteristics could be used to personalise the route of surgery in order to maximise the potential benefit from 


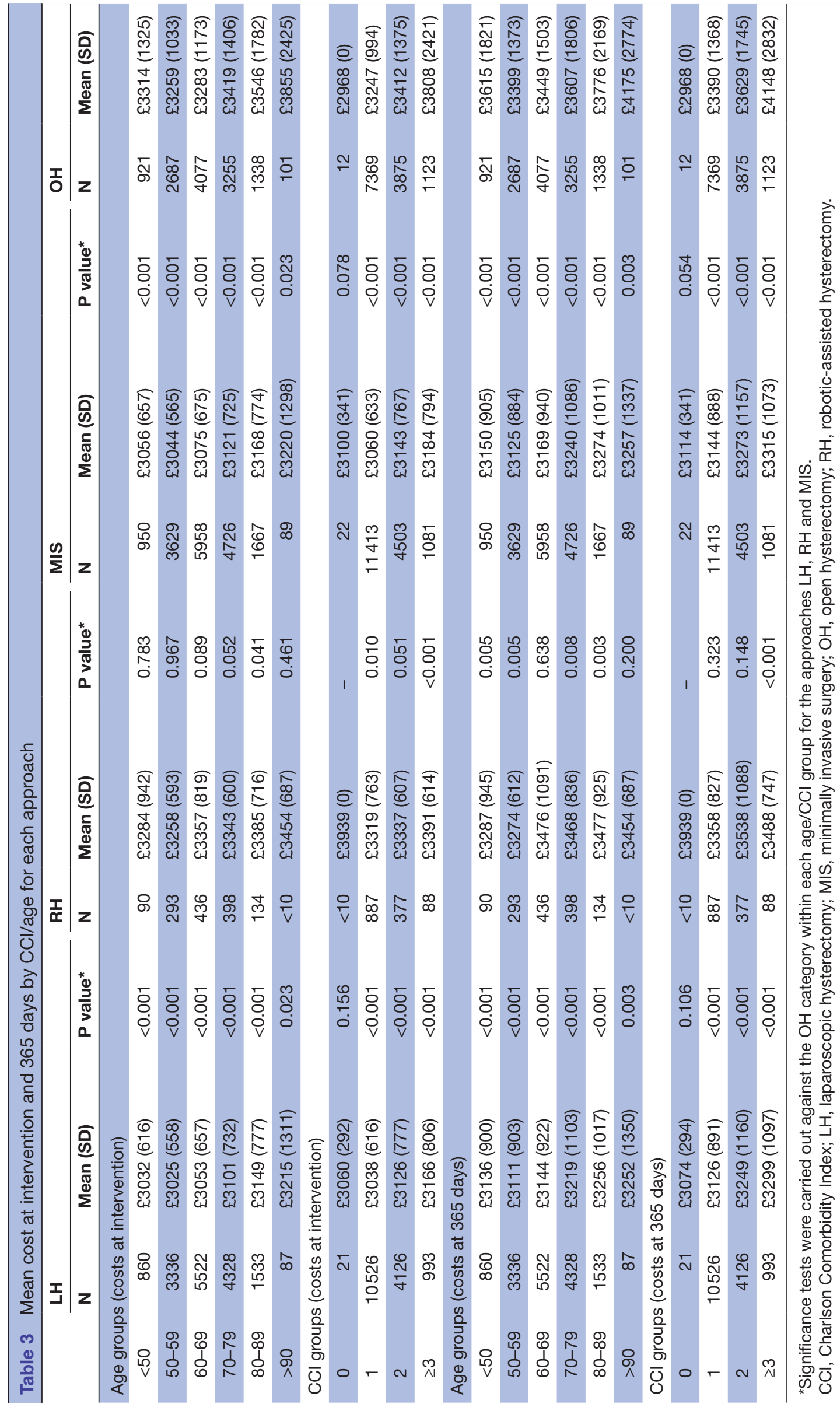




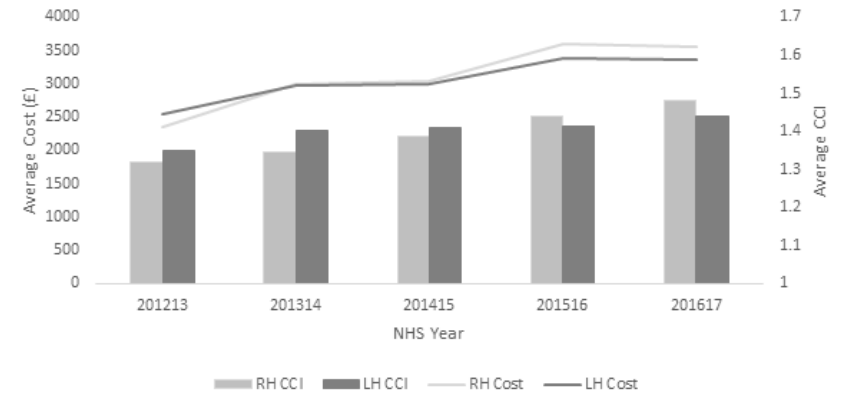

Figure 1 Intervention cost and $\mathrm{CCl}$ over time. The average cost and $\mathrm{CCl}$ of $\mathrm{RH}$ and $\mathrm{LH}$ over time. $\mathrm{CCl}$, Charlson Comorbidity Index; LH, laparoscopic hysterectomy; NHS, National Health Service; RH, robotic-assisted hysterectomy.

MIS and reduce the rate of OH. Prospective RCTs are the gold standard study design however can be challenging to perform and may be subject to many biases, including patient selection, if a surgeon has a greater preference for one surgical modality over another. Also, RCTs can take many years to complete accrual, for example, $\mathrm{LACC},{ }^{31}$ by which time the current robotic/laparoscopic platforms may be obsolete. Instead, the use of real-world data in a propensity score matching study may enable matching of key patient characteristics to give results in a more timely manner. ${ }^{32}$ The development and adoption of prognostic and risk-stratifying biomarkers in the future may also inform decisions on the optimum route of surgery thereby enabling more personalised management. ${ }^{33-35}$

\section{Strengths and limitations}

The key strength of the study is in the number of patients which can be analysed by using the HES Database. This gives strength to the study's findings as it is representative of all procedures via the NHS in England. Due to RH being a newer surgery approach, the number of patients is much lower compared with the other surgery

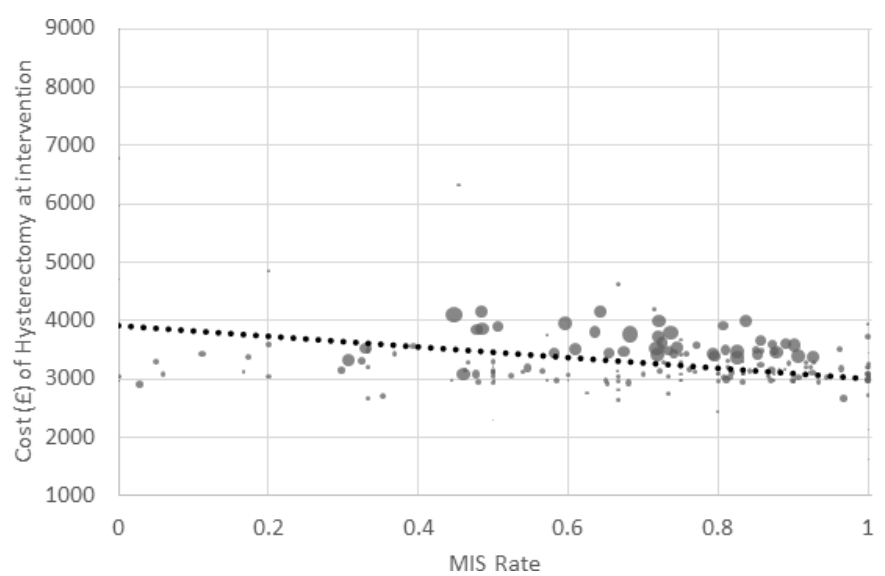

Figure 2 Average provider cost of hysterectomy per provider by MIS rate in 2016/2017. The association between provider volume, MIS rate and surgical cost at intervention. Provider volume is represented by the size of the bubble with a larger bubble representing a higher provider volume. MIS, minimally invasive surgery. approaches. In addition, we must consider the impact of a learning curve of RH and that in the earlier years it may not had been used to full efficiency. As we had a number of years of the HES Database, we could analyse any potential trends across surgical approaches and the year.

As we have previously described, ${ }^{8}$ the HES Database does have limitations, primarily it only covers NHS-funded care, the reliability of coding and lacks oncological details of stage/histology. A limitation of the CCI calculated using the HES data is that people with no hospital attendance 12 months prior to intervention are classified as having no comorbidities instead of missing; but as the NHS is free at the point of contact, the HES Database is extensive at capturing all hospital-reported comorbidities in England. There will be a proportion of patients with advanced disease that require open surgery due to requiring a more extensive cytoreductive procedure and HES data are not able to differentiate these cases from early-stage disease that is being treated through open surgery. The analysis comparing LH and RH should however not be impacted by stage of disease. In addition, there are limitations with the HES data with the recording of severity of patient comorbidities, in particular obesity, since a numerical value for BMI is not included and therefore the obesity classification could be applied to any patient with a BMI $>30 \mathrm{~kg} / \mathrm{m}^{2}$.

The capital and maintenance costs of $\mathrm{RH}$ have also not been included since these costs vary dramatically across different healthcare settings and there would be a need to also include similar costs for laparoscopic and open surgery. In addition, the robotic surgery equipment is often used by a wide group of specialties in a hospital setting and it would be infeasible to apply capital and maintenance costs to one surgery modality. ${ }^{15}$

\section{Interpretation}

In conclusion, $\mathrm{LH}$ was associated with the lowest and $\mathrm{OH}$ the greatest mean cost per procedure. Patient factors have an impact on the cost of MIS procedures and further research is needed to compare the costs in matched populations of women undergoing $\mathrm{LH}$ and $\mathrm{RH}$, since there appears to be selection bias in the choice of procedure being performed.

Acknowledgements We would like to thank Harvey Walsh for facilitating access to Hospital Episode Statistics (HES) data via a Standard Extract Re-use Agreement issued by the Health \& Social Care Information Centre 2018.

Contributors ELM, TI, GM and AM contributed to the conceptualisation and study design. Data analysis and interpretation were performed by ELM, TI, GM, AM and PS. Figures and tables were created by ELM, GM and AM. All authors were involved in the writing or review of the manuscript and approved the final version.

Funding This study was funded by Intuitive Surgical.

Disclaimer Intuitive Surgical did not have any involvement with the study design, data analysis and writing of the manuscript.

Competing interests ELM and TI perform Da'Vinci robotic gynaecological surgery (Intuitive Surgical) and are members of the British and Irish Association of Robotic Surgeons (BIARGS), which is supported by Intuitive Surgical and other robotics/laparoscopic companies to hold education/training events. ELM has been awarded research grants from Intuitive Surgical and Hope Against Cancer for unrelated studies, serves on advisory boards for Inivata and GlaxoSmithKline and 
has received speaker fees from GlaxoSmithKline. TI has done two days of paid consultancy work for Medtronic. GM and AM from HCD Economics were funded by Intuitive Surgical. None of the clinicians (ELM, PS, TI) received funding from Intuitive Surgical for this study. The authors declare no other potential conflict of interest.

Patient consent for publication Not required

Ethics approval The HES Database is managed by the NHS Digital and is available for research without ethical approval. All the authors consent to publication.

Provenance and peer review Not commissioned; externally peer reviewed.

Data availability statement Data may be obtained from a third party and are not publicly available. Data analysed in this study are available through NHS Digital.

Supplemental material This content has been supplied by the author(s). It has not been vetted by BMJ Publishing Group Limited (BMJ) and may not have been peer-reviewed. Any opinions or recommendations discussed are solely those of the author(s) and are not endorsed by BMJ. BMJ disclaims all liability and responsibility arising from any reliance placed on the content. Where the content includes any translated material, BMJ does not warrant the accuracy and reliability of the translations (including but not limited to local regulations, clinical guidelines, terminology, drug names and drug dosages), and is not responsible for any error and/or omissions arising from translation and adaptation or otherwise.

Open access This is an open access article distributed in accordance with the Creative Commons Attribution Non Commercial (CC BY-NC 4.0) license, which permits others to distribute, remix, adapt, build upon this work non-commercially, and license their derivative works on different terms, provided the original work is properly cited, appropriate credit is given, any changes made indicated, and the use is non-commercial. See: http://creativecommons.org/licenses/by-nc/4.0/.

\section{ORCID iD}

Esther L Moss http://orcid.org/0000-0002-2650-0172

\section{REFERENCES}

1 Janda M, Gebski V, Brand A, et al. Quality of life after total laparoscopic hysterectomy versus total abdominal hysterectomy for stage I endometrial cancer (LACE): a randomised trial. Lancet Oncol 2010;11:772-80.

2 Graves N, Janda M, Merollini K, et al. The cost-effectiveness of total laparoscopic hysterectomy compared to total abdominal hysterectomy for the treatment of early stage endometrial cancer. BMJ Open 2013;3:e001884.

3 NICE. Interventional procedure overview of laparoscopic hysterectomy (including laparoscopic total hysterectomy and laparoscopically assisted vaginal hysterectomy) for endometrial cancer, 2010. Available: https://www.nice.org.uk/guidance/ipg356/ documents/laparoscopic-hysterectomy-including-laparoscopic-totalhysterectomy-and-laparoscopic-assisted-vaginal-hysterectomy-forendometrial-cancer-overview2 [Accessed 21 Aug 2019].

4 Mäenpää MM, Nieminen K, Tomás El, et al. Robotic-assisted vs traditional laparoscopic surgery for endometrial cancer: a randomized controlled trial. Am J Obstet Gynecol 2016;215:588. e1-e7.

5 Ind $\mathrm{T}$, Laios $\mathrm{A}$, Hacking $\mathrm{M}$, et al. A comparison of operative outcomes between standard and robotic laparoscopic surgery for endometrial cancer: a systematic review and meta-analysis. Int J Med Robot 2017;13:e1851.

6 Teljeur C, O'Neill M, Moran PS, et al. Economic evaluation of robot-assisted hysterectomy: a cost-minimisation analysis. BJOG 2014;121:1546-53.

7 Polan RM, Tanner EJ, Barber EL. Minimally invasive surgery rate as a quality metric for endometrial cancer. J Minim Invasive Gynecol 2020;27:1389-94.

8 Moss EL, Morgan G, Martin AP, et al. Surgical trends, outcomes and disparities in minimal invasive surgery for patients with endometrial cancer in England: a retrospective cohort study. BMJ Open 2020;10:e036222.

9 Winter ML, Leu S-Y, Lagrew DC, et al. Cost comparison of roboticassisted laparoscopic hysterectomy versus standard laparoscopic hysterectomy. J Robot Surg 2015;9:269-75.

10 TEJ I, Marshall C, Hacking M. Introducing robotic surgery into an endometrial cancer service-a prospective evaluation of clinical and economic outcomes in a UK institution. Int J Med Robot Comput Assist Surg 2016;12:137-44.

11 NHS Digital. Hospital episode statistics (HES). Available: https:// digital.nhs.uk/data-and-information/data-tools-and-services/dataservices/hospital-episode-statistics. [Accessed 6 Aug 2019].
12 Government D for C and L. The English index of multiple deprivation (IMD) 2015-Guidance, 2015. Available: https://www.gov.uk/ government/statistics/english-indices-of-deprivation-2015 [Accessed 22 Feb 2019].

13 Quan $\mathrm{H}$, Li B, Couris CM, et al. Updating and validating the Charlson comorbidity index and score for risk adjustment in hospital discharge Abstracts using data from 6 countries. Am J Epidemiol 2011;173:676-82.

14 Daidone S, Street A. Estimating the costs of specialised care. SSRN Electron J 2012.

15 Camp C, O'Hara J, Hughes D, et al. Short-Term outcomes and costs following partial nephrectomy in England: a population-based study. Eur Urol Focus 2018;4:579-85.

16 Jones AM. Models for health care, 2010.

17 Abitbol J, Munir A, How J, et al. The shifting trends towards a robotically-assisted surgical interface: clinical and financial implications. Health Policy Technol 2020;9:157-65.

18 Korsholm M, Gyrd-Hansen D, Mogensen O, et al. Long term resource consequences of a nationwide introduction of robotic surgery for women with early stage endometrial cancer. Gynecol Oncol 2019;154:411-9.

19 Holtz DO, Miroshnichenko G, Finnegan MO, et al. Endometrial cancer surgery costs: robot vs laparoscopy. J Minim Invasive Gynecol 2010;17:500-3.

20 Cusimano MC, Simpson AN, Dossa F, et al. Laparoscopic and robotic hysterectomy in endometrial cancer patients with obesity: a systematic review and meta-analysis of conversions and complications. Am J Obstet Gynecol 2019;221:410-28.

21 Rolston A, Spencer RJ, Kevin Reynolds R, et al. Factors associated with outcomes and inpatient 90-day cost of care in endometrial cancer patients undergoing hysterectomy - implications for bundled care payments. Gynecol Oncol 2018;150:106-11.

22 Ind TEJ, Marshall C, Hacking M, et al. The effect of obesity on clinical and economic outcomes in robotic endometrial cancer surgery. Robot Surg 2017:4:33-7.

23 Tarr ME, Brancato SJ, Cunkelman JA, et al. Comparison of postural ergonomics between laparoscopic and robotic sacrocolpopexy: a pilot study. J Minim Invasive Gynecol 2015;22:234-8.

24 Moss EL, Sarhanis P, Ind T, et al. Impact of obesity on surgeon ergonomics in robotic and Straight-Stick laparoscopic surgery. J Minim Invasive Gynecol 2020;27:1063-9.

25 Plerhoples TA, Hernandez-Boussard T, Wren SM. The aching surgeon: a survey of physical discomfort and symptoms following open, laparoscopic, and robotic surgery. J Robot Surg 2012;6:65-72.

26 Park A, Lee G, Seagull FJ, et al. Patients benefit while surgeons suffer: an impending epidemic. J Am Coll Surg 2010;210:306-13.

27 Herling SF, Palle C, Møller AM, et al. Cost-analysis of roboticassisted laparoscopic hysterectomy versus total abdominal hysterectomy for women with endometrial cancer and atypical complex hyperplasia. Acta Obstet Gynecol Scand 2016;95:299-308.

28 Janda M, Armfield NR, Kerr G, et al. Surgical approach to hysterectomy and barriers to using minimally invasive methods. Aust N Z J Obstet Gynaecol 2018;58:690-5.

29 Keurentjes JHM, Briët JM, de Bock GH, et al. Surgical volume and conversion rate in laparoscopic hysterectomy: does volume matter? A multicenter retrospective cohort study. Surg Endosc 2018:32:1021-6.

30 Radosa JC, Radosa MP, Schweitzer PA, et al. Impact of different intraoperative $\mathrm{CO}_{2}$ pressure levels ( 8 and $15 \mathrm{mmHg}$ ) during laparoscopic hysterectomy performed due to benign uterine pathologies on postoperative pain and arterial $\mathrm{pCO}_{2}$ : a prospective randomised controlled clinical trial. BJOG 2019;126:1276-85.

31 Ramirez PT, Frumovitz M, Pareja R, et al. Minimally invasive versus abdominal radical hysterectomy for cervical cancer. N Engl J Med 2018;379:1895-904.

$32 \mathrm{Tan} \mathrm{JKH}, \mathrm{Ng}$ JJ, Yeo M, et al. Propensity score-matched analysis of early outcomes after laparoscopic-assisted versus open pancreaticoduodenectomy. ANZ J Surg 2019;89:E190-4.

33 Moss EL, Gorsia DN, Collins A, et al. Utility of circulating tumor DNA for detection and monitoring of endometrial cancer recurrence and progression. Cancers 2020;12:2231.

34 Crigna AT, Samec M, Koklesova L, et al. Cell-free nucleic acid patterns in disease prediction and monitoring-hype or hope? Epma J 2020;11:603-27.

35 Qian S, Golubnitschaja O, Zhan X. Chronic inflammation: key player and biomarker-set to predict and prevent cancer development and progression based on individualized patient profiles. Epma $J$ 2019;10:365-81. 